\title{
COMMENTARY
}

\section{From bench to bedside}

\author{
Colin L Verdant* \\ See related research by Pranskunas et al., http://ccforum.com/content/16/3/R83
}

\begin{abstract}
Because the microcirculation has emerged as an important reanimation target, appropriate methods to monitor the microcirculatory function are crucial. Several teams have now succeeded in crossing this bridge from bench to bedside, but the choice of the tissues of interest remains a debate. The potential accessible vascular beds that doctors could use in reanimation strategies and the relationship of these beds to more relevant microcirculatory ones are important issues to address.
\end{abstract}

In the previous issue of Critical Care, Pranskunas and colleagues [1] worked on expanding our knowledge of the assessment of the microcirculation from bench to the bedside. The paradox between the macro- and microcirculation is now well known. Despite having an apparent macrohemodynamic stability, an important proportion of patients with sepsis experience microcirculatory dysfunctions that carry significant morbidity and mortality $[2,3]$. If a patient presents with a macrohemodynamic vascular collapse, we know where to start with our reanimation strategies [4]. The persisting clinical challenge is the macrohemodynamically resuscitated patient who continues to show signs of tissue perfusion failure. Since the microcirculation emerges as an important reanimation target, one of the great challenges of the last few years has been to bring to the bedside convenient and effective ways of assessing the patient's microcirculatory function. Outside of the operating theater, very few vascular beds can be assessed easily and repeatedly. Are there surrogate vascular beds that could be used, and what are their relationships to more relevant microcirculatory units like the gut and the brain microcirculations? The work of Pranskunas and colleagues provides some answers to these difficult questions.

*Correspondence: cverdant@mac.com

Hôpital du Sacré-Coeur de Montréal, 5400 boul. Gouin Ouest, Montréal, Québec, Canada, H4J 2L7
In a porcine model of septic shock, the authors compared the microvasculature of the sublingual region, the small and large intestines, and the conjunctiva. The authors report a relatively good correlation between the different vascular beds after three hours. However, they observed the loss of this relationship at the end of the experiment, at five hours. Does this imply a timedependent relationship, or could there be factors in the model itself that lead to artifacts over time?

The authors acknowledge that their model differs from the hyperdynamic state that we are used to seeing in reanimated patients with sepsis. In fact, four of the animals died just 15 minutes after the bacterial exposure - a situation that reproduces more the macrohemodynamics that are described in acute endotoxemic models that have been challenged with regard to their clinical relevance [5]. With important decreases in cardiac indices, it might not be surprising to observe a shutdown of most of the downstream vascular beds. One hypothesis is that, during the preparation of the inoculums, a significant amount of dead bacteria and endotoxin accumulated in the preparation; this could explain the hemodynamic collapse observed in these animals. In a previous study, we had to take extreme care to obtain bacteria in their exponential growing phase and inoculums had to be washed several times to limit the accumulation of endotoxins [6].

Technical factors such as the desiccation of the tissues and the surgery also have to be considered. Even if the microcirculation of the sham animal remained well perfused during the whole experiment, the effects of these manipulations, like the ones seen in second hit injury models, may be potentiated by the sepsis [7]. Accordingly, a rather short recovery period may be insufficient to allow a proper stabilization of the animals. It should be noted that a significant amount of fluid was needed in the sham animals and that, at 5 hours, their cardiac indices were significantly increased (by almost $40 \%$ ). This suggests a form of inflammatory response and third spacing secondary to the surgical preparation.

The authors also suggest a relationship between the microcirculation of the conjunctiva and that of the brain. One could argue that, because the tongue and the gut share similar embryologic origins, the microcirculatory 
changes that occur in the gut and in the sublingual region during sepsis or in response to vasopressor therapy could be related [8]. Can the same argument be made for the conjunctiva and the brain? The sclera is derived from the overlying surface of the ectoderm [9]. It has been postulated that the changes of the conjunctival vasculature would better correlate with the peripheral vessels of the brain [10]. As it is derived from the anterior neural plate, the retina might be a better surrogate of brain perfusion.

In addition, it is more likely that the brain microcirculation behaves independently because of important factors such as cerebral autoregulation, specificity of the blood-brain barrier, and the parameters regulating intracranial pressure [11,12]. The outer surface of the eye, in contrast, could be more prone to local factors and swelling due to a variety of situations that can be encountered in the critically ill patient [13].

In conclusion, Pranskunas and colleagues have made an important contribution to the effort to assess the brain microcirculation by monitoring the eye. Their results must be validated in further studies using more clinically relevant models that include a simultaneous examination of the brain microcirculation. This will lead to a better understanding of the 'tongue-gut' and the 'brain-eye' relationships.

Competing interests

The author declares that he has no competing interests.

Published: 6 July 2012

\section{References}

1. Pranskunas A, Pilvinis V, Dambrauskas Z, Rasimaviciute R, Planciuniene R, Dobozinskas P, Veikutis V, Vaitkaitis D, Boerma EC: Early course of microcirculatory perfusion in eye and digestive tract during hypodynamic sepsis. Crit Care 2012, 16:R83.

2. De Backer D, Creteur J, Preiser J-C, Dubois M-J, Vincent J-L: Microvascular blood flow is altered in patients with sepsis. Am J Respir Crit Care Med 2002, 166:98-104.

3. Sakr Y, Dubois M-J, De Backer D, Creteur J, Vincent J-L: Persistent microcirculatory alterations are associated with organ failure and death in patients with septic shock. Crit Care Med 2004, 32:1825-1831.

4. Rivers E, Nguyen B, Havstad S, Ressler J, Muzzin A, Knoblich B, Peterson E, Tomlanovich M; Early Goal-Directed Therapy Collaborative Group: Early goaldirected therapy in the treatment of severe sepsis and septic shock. NEngl J Med 2001, 345:1368-1377.

5. Piper RD, Cook DJ, Bone RC, Sibbald WJ: Introducing Critical Appraisal to studies of animal models investigating novel therapies in sepsis. Crit Care Med 1996, 24:2059-2070.

6. Verdant CL, De Backer D, Bruhn A, Clausi CM, Su F, Wang Z, Rodriguez H, Pries $A R$, Vincent JL: Evaluation of sublingual and gut mucosal microcirculation in sepsis: a quantitative analysis. Crit Care Med 2009, 37:2875-2881.

7. Gierer P, Hoffmann JN, Mahr F, Menger MD, Mittlmeier T, Gradl G, Vollmar B: Sublethal trauma model with systemic endotoxemia for the study of microcirculatory disorders after the second hit. J Surg Res 2008, 147:68-74.

8. Moore KL, Persaud TV: The Developing Human. Philadelphia: Saunders: 1993:496.

9. Barishak YR: Embryology of the eye and its adnexae. Dev Ophthalmo/ 1992, 24:1-142.

10. Dexel T, Böhme H, Schmidt P, Haslbeck M, Mehnert H: Investigation of conjunctival vessels in diabetics with and without retinopathy by means of a microcirculation-index. Bibl Anat 1977, (16 Pt 2):442-444.

11. Wan Z, Sun S, Ristagno G, Weil MH, Tang W: The cerebral microcirculation is protected during experimental hemorrhagic shock. Crit Care Med 2010, 38:928-932.

12. Taccone FS, Su F, Pierrakos C, He X, James S, Dewitte O, Vincent JL, De Backer D: Cerebral microcirculation is impaired during sepsis: an experimental study. Crit Care 2010, 14:R140.

13. Grixti A, Sadri M, Edgar J, Datta AV: Common ocular surface disorders in patients in intensive care units. Ocul Surf 2012, 10:26-42.

doi:10.1186/cc11394

Cite this article as: Verdant CL: From bench to bedside. Critical Care 2012, 16:136. 